\title{
UMA ABORDAGEM SISTÊMICA SOBRE AS IMPLICAÇÕES ENTRE A FRAGMENTAÇÃO DAS ÁREAS VERDES E O AMBIENTE TÉRMICO DO ESPAÇO URBANO
}

\author{
Marcelo Paes de Barros \\ Professor do Departamento de Física/ IF/ UFMT, Linha de Pesquisa: Análise Microclimática em Sistemas \\ Urbanos, E-mail: mpb9@terra.com.br
}

\section{Carlo Ralph De Musis}

Professor da Universidade de Cuiabá/ UNIC, Professor do Programa de Pós-Graduação em Física Ambiental, Linha de Pesquisa: Análise Microclimática em Sistemas Urbanos, E-mail: carlo.demusis@gmail.com

http://dx.doi.org/10.5902/223611707705

\section{RESUMO}

O artigo apresenta os resultados de um estudo que procurou investigar a magnitude e a extensão da influência dos fragmentos arbóreos sobre os ambientes térmicos de espaços urbanizados da cidade de Cuiabá, MT. Os principais instrumentos utilizados foram o sensoriamento remoto, no exame de uma imagem CBERS de 20 de junho de 2009, as medições móveis e os sistemas de informações geográficas para obter uma visão macro do complexo urbano. Os resultados confirmaram a influência dos fragmentos de vegetação arbórea sobre a temperatura do ar dos ambientes analisados, variando entre $200 \mathrm{~m}$ e $500 \mathrm{~m}$, em função do horário e da estação, seca ou chuvosa. Verificou-se que a fragmentação das áreas verdes, descrita pela dimensão fractal, atua de forma mais decisiva nos ambientes térmicos com baixos percentuais de área vegetada, sendo que nesses casos uma vegetação menos fragmentada resultou em menores temperaturas do ar.

Palavras-chave: Clima urbano, análise fractal, padrão da paisagem, sensoriamento remoto.

\section{ABSTRACT}

This paper presents the results of a study that investigate the magnitude and extent of the influence of fragments of vegetated area on thermal environments of urbanized areas of the city of Cuiabá, MT. The main tools were remote sensing, on examination of a CBERS acquired on June 20,2009 , mobile measurements and geographical information systems to obtain a macro view of urban complex. The results confirmed the influence of fragments of woody vegetation on the air temperature environments analyzed, ranging between $200 \mathrm{~m}$ and $500 \mathrm{~m}$, depending on the time and station, dry or rainy. It was found that the fragmentation of green areas, described by the fractal dimension, acts more decisively in thermal environments with low percentages of vegetated area, and in such cases a less fragmented vegetation resulted in lower air temperatures.

Keywords: Urban climate, fractal analysis, landscape pattern, remote sensing.

\section{INTRODUÇÃO}

O impulso agrícola que, a partir da década de 1970, transformou o cerrado matogrossense em quase sua totalidade em plantações, principalmente de soja, foi um dos motivos para que as principais cidades do estado sofressem uma rápida e desordenada urbanização. $\mathrm{A}$ 
ausência de um planejamento resultou na ocupação ilegal de áreas periféricas e invasões das áreas verdes remanescentes da cidade, ações que produziram graves problemas sociais e ambientais.

Na cidade de Cuiabá a disposição urbana, os sistemas de tráfego, resultados dessa forma de ocupação, e as características climáticas da região, em uma combinação insatisfatória, produziram situações de ilhas de calor em alguns ambientes intra-urbanos. Esse aumento das temperaturas da superfície (Land Surface Temperature - LST) e do ar acima dos ambientes urbanos, em resposta a introdução de materiais artificiais substituindo a cobertura natural, é o fenômeno mais significativo do clima urbano. O consequente aumento na razão de Bowen ${ }^{1}$ justifica esse aquecimento de todo o ar do ambiente produzindo no espaço urbanizado, comparativamente ao ambiente natural, alterações dramáticas nos fluxos de energia na superfície e na atmosfera próxima (OKE, 1982).

Por outro lado, algumas áreas verdes inseridas neste mesmo espaço urbano são indicadores de sustentabilidade, de forma que a interação dinâmica entre o ambiente e esses fragmentos de vegetação cria assinaturas únicas dos parâmetros climáticos em função da extensão e do padrão de distribuição espacial desta vegetação. Neste sentido vários trabalhos, utilizando diferentes técnicas, mostraram a importância de se incorporar no planejamento dos espaços abertos do ambiente construído os benefícios dos indivíduos arbóreos como reguladores do sistema clima destes ambientes (DIMOUDI \& NIKOLOPOULOU, 2003; FUKUI, 2003; YU \& WONG, 2006; JUSUF et al., 2007; PEZZUTO, 2007; ABREU \& LABAKI, 2010).

Essas assinaturas diferenciadas ajudaram a formulação da hipótese deste trabalho, de que existe uma relação entre o ambiente térmico de um lugar e o padrão espacial das áreas vegetadas do seu entorno próximo. Assim, o objetivo geral deste estudo foi avaliar a força e a extensão da influência das áreas verdes e sua fragmentação sobre o ambiente térmico de um lugar, de forma a contribuir para o melhor entendimento da relação do clima local com a estrutura urbana e fornecer subsídios para uma política de planejamento voltada a uma melhor ambiência nos espaços abertos das cidades.

\section{MATERIAIS E MÉTODOS}

\section{1 Área de Estudo}

Localizada na porção central da América do Sul, nas coordenadas geográficas 150 35' 56" latitude Sul e 56ㅇ 06' 01" longitude Oeste, na zona intertropical do Planeta, a Região Metropolitana do Vale do Rio Cuiabá (RMVRC) tem seu clima identificado prioritariamente pela temperatura. Segundo a classificação de Köppen o clima da região é do tipo Aw, típico do regime tropical de savana com duas estações bem definidas, uma seca, que se prolonga de abril/maio a setembro/outubro, e outra chuvosa. As temperaturas médias anuais oscilam entre $25^{\circ} \mathrm{C}$ e $26{ }^{\circ} \mathrm{C}$, enquanto as máximas, frequentemente, ultrapassam $35^{\circ} \mathrm{C}$ durante quase o ano todo (MAITELLI, 2005). A ocorrência de períodos de curta duração com temperatura baixa alternando-se a temperaturas moderadas ou elevadas durante a estação seca é uma característica marcante do clima na RMVRC (CAMPELO JÚNIOR et al., 1991).

\subsection{Apresentação dos Bairros do Estudo}

Para a realização deste trabalho, em virtude da metodologia utilizada para o seu desenvolvimento, o método do transecto móvel, foram escolhidos apenas 5 bairros da região

\footnotetext{
${ }^{1}$ Relação entre os fluxos de calor sensível e latente.
} 
sudeste da cidade, onde o processo de urbanização se apresentou mais intenso nos últimos 30 anos. A escolha dos bairros foi baseada nos aspectos da proximidade entre suas áreas, da concentração de áreas construídas e áreas verdes, do adensamento populacional e da complexidade do uso do solo (Figura 01).

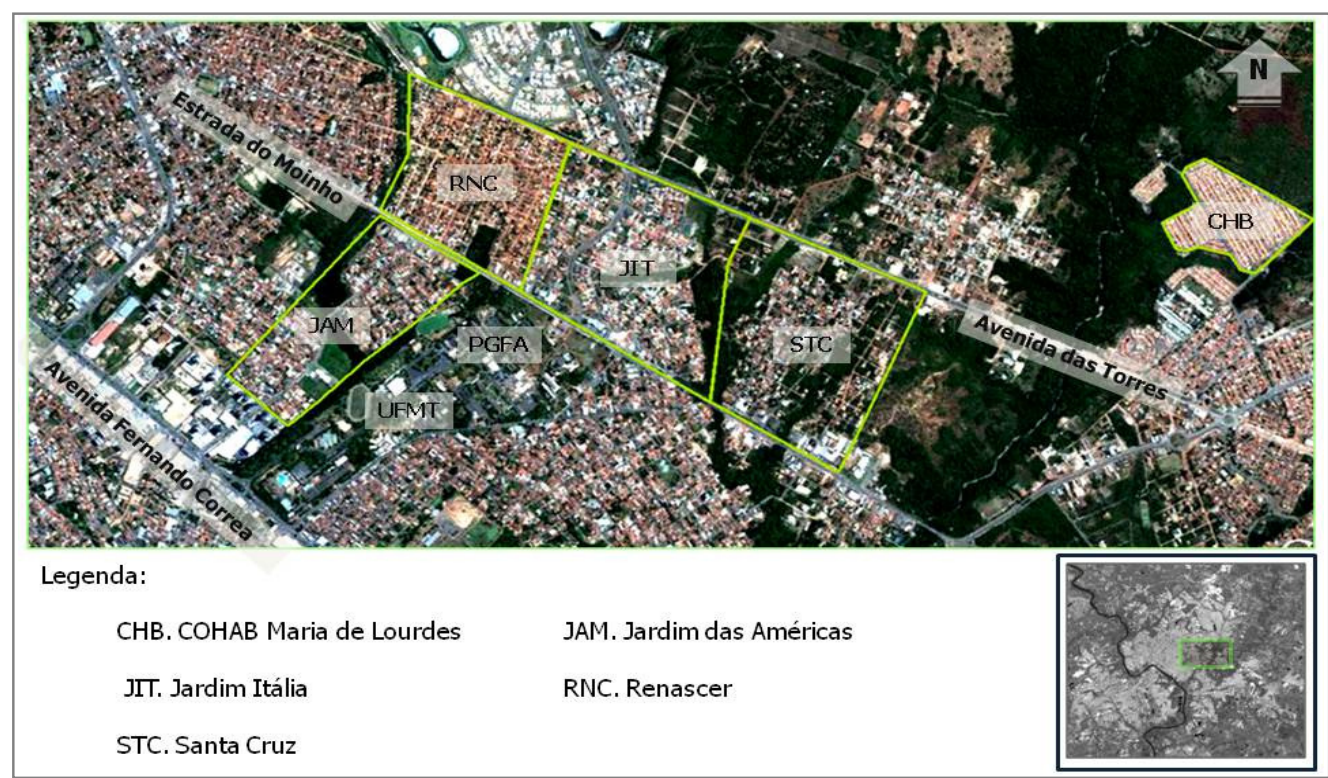

Figura 01 - Área de estudo

Fonte: Google Earth, 2010

\subsubsection{Fonte de dados}

Os dados e as informações sobre uso da terra e da urbanização para caracterizar a atual ocupação do solo nas áreas dos bairros selecionados e arredores próximos foram extraídos da imagem do satélite CBERS-2B (China-Brasil Earth Resources Satellite) órbita/ponto 116_E/117_5 com passagem em 20 de junho de 2009. Além desta imagem outras três foram utilizadas para avaliar a direção do vetor crescimento da cidade nos últimos trinta anos:

a. LANDSAT-3, órbita/ponto 243/71, com passagem em 03 de janeiro de 1980;

b. LANDSAT-5, órbita/ponto 226/71, com passagem em 28 de maio de 1995;

c. LANDSAT-5, órbita/ponto 226/71, com passagem em 18 de março de 2010.

Todas as imagens, fornecidas gratuitamente pelo Instituto Nacional de Pesquisas Espaciais (INPE), foram selecionadas através do catálogo de imagens da Divisão de Geração de Imagens do Instituto Nacional de Pesquisas Espaciais (DGI-INPE) seguindo o critério de menor cobertura de nuvens.

De acordo com os objetivos do trabalho, para as imagens LANDSAT mostrou-se mais adequada, para uma maior separabilidade do uso do solo urbano, a classificação nãosupervisionada, utilizando-se as combinações das bandas 1 e 5 para o sensor TM, e as bandas 5 e 6 para o sensor MSS, realizada pelo algoritmo MAXWER, com limiar de aceitação de $100 \%$. Para sintetizar e combinar as informações das imagens CBERS dos sensores HRC e CCD foi utilizada a 
técnica de fusão de imagens pelo método IHS. Esta técnica possibilitou integrar a melhor resolução espacial da banda pancromática do sensor HRC com a melhor resolução espectral das demais bandas do sensor CCD, produzindo imagens coloridas de melhor qualidade que reúnem ambas as características.

Todo o tratamento digital das imagens foi realizado com a utilização do aplicativo SPRING v.5.1.3 (INPE, 2009), gratuitamente oferecido pelo INPE.

\subsection{Medições Microclimáticas}

O ambiente térmico de cada microclima dos bairros foi caracterizado pelo método de medições móveis. Este método e sua instrumentação utilizados neste trabalho foram adaptados com base nos trabalhos realizados por Kaiser e Faria (2001), aplicado em Bauru, SP, Pezzuto (2007), em Campinas, SP e Barros et al. (2010), em Cuiabá, MT.

A partir de um estudo prévio foram selecionados cinco postos de controle (PCs), um em cada bairro, locados na porção central destes, além de outros 45 pontos de referência (PRs), totalizando 250 pontos distribuídos pela área de estudo. Para que expressassem de forma mais próxima o ambiente térmico real deste espaço urbano estes pontos foram escolhidos em função das diferentes configurações de uso e ocupação do solo, proximidades de vegetação e corpos d'água, diferentes tipos de atividades, altura de edificações, densidade construída e trânsito de veículos.

A delimitação do trajeto para as medições transversais de temperatura do ar por instrumento acoplado a um automóvel, medições móveis, seguindo as recomendações dos trabalhos de Saaroni et al. (2000) e Pezzuto (2007), procurou estabelecer uma rota racional, em função do trânsito local, a ser percorrida no menor tempo possível, definida em eixos paralelos que atravessassem os PCs e PRs.

A implementação do método contou com a instalação do conjunto de medidores, termômetro digital portátil com data-logger e sensor de par termoelétrico tipo K, na lateral do veículo para realização das medições móveis. Para a localização automática dos pontos percorridos pelo veículo foi utilizado um GPS que, sincronizado com o registrador da temperatura do ar, programado para registrar e armazenar dados a cada 10 segundos, garantiu que todo ponto com registro de temperatura do ar fosse devidamente georreferenciado.

Com exceção do horário das $02 \mathrm{~h}$, as medições móveis aconteceram nos horários padrões recomendados pela Organização Mundial de Meteorologia (WMO) para as principais observações meteorológicas de um dia típico, às $00 \mathrm{~h}, 06 \mathrm{~h}, 12 \mathrm{~h}$ e $18 \mathrm{~h}$ GMT (Greenwich Meridian Time), correspondentes às $20 \mathrm{~h}, 02 \mathrm{~h}, 08 \mathrm{~h}$ e $14 \mathrm{~h}$, horário local. As medições tinham início, aproximadamente, trinta minutos antes do horário padrão e, dependendo das condições locais de trânsito, eram completadas após uma hora e 15 minutos.

Para a correção do tempo tardio foram instalados registradores da temperatura do ar com data-logger nos PCs dos bairros, as medições fixas. Estes registros foram utilizados para corrigir para os horários padrões das medições as medidas móveis de cada bairro, a partir da evolução da temperatura do ar na porção central do mesmo.

As medições aconteceram em quatro períodos ao longo de um ano, dois em cada estação, em datas definidas pela disponibilidade da equipe de medições e pela previsão de três dias, no mínimo, de condições meteorológicas estáveis, de céu claro, sem chuva e com ventos reduzidos. As primeiras simulações de medições tiveram início em 03 de maio de 2010, estendendo-se até 08 de outubro de 2011. A Tabela 01 apresenta os dias de medições para coleta de dados. 
Tabela 01 - Períodos de medições

\begin{tabular}{cc}
\hline Estação & Período de Coleta \\
\hline Seca & 06 a 10 de setembro de 2010 \\
Chuva & 13 a 17 de dezembro de 2010 \\
Chuva & 18 a 22 de abril de 2011 \\
Seca & 08 a 12 de agosto de 2011 \\
\hline
\end{tabular}

\subsection{Classificação das Imagens}

Neste processo foi utilizada uma composição das imagens reamostradas do satélite CBERS-2B dos sensores HRC e CCD, bandas 2, 3 e 4. Esta composição, segundo Gonçalves et al. (2005), permite uma melhor separabilidade de usos intra-urbanos com maior precisão graças à melhor resolução espacial, de $2,5 \mathrm{~m}$, do sensor HRC.

A classificação foi realizada pelo algoritmo MAXWER, supervisionada por pixel e com limiar de aceitação de $100 \%$. Neste recorte do espaço urbano foram identificadas, conforme classificação proposta por Novack et al. (2007), cinco classes de ocupação dos solos: uma para superfícies de corpos de água; duas classes associadas às áreas com vegetação, áreas de vegetação arbórea, correspondentes aos dosséis das árvores, e áreas de vegetação de gramíneas; duas para alvos de elevada reflectância, solos expostos e áreas urbanizadas, independente da altura das construções (Tabela 02).

Tabela 02 - Classes e códigos de entrada para o SPRING

\begin{tabular}{cc}
\hline Classe & Código \\
\hline Corpos D’água & 1 (Azul) \\
Vegetação Arbórea & 2 (Verde escuro) \\
Vegetação Rasteira & 3 (Verde claro) \\
Área Urbanizada & 4 (Vermelho) \\
Solo Nu & 5 (Rosa) \\
\hline
\end{tabular}

Como resultado deste processo foram geradas as imagens dos bairros classificadas automaticamente segundo essas categorias (Figura 02). 


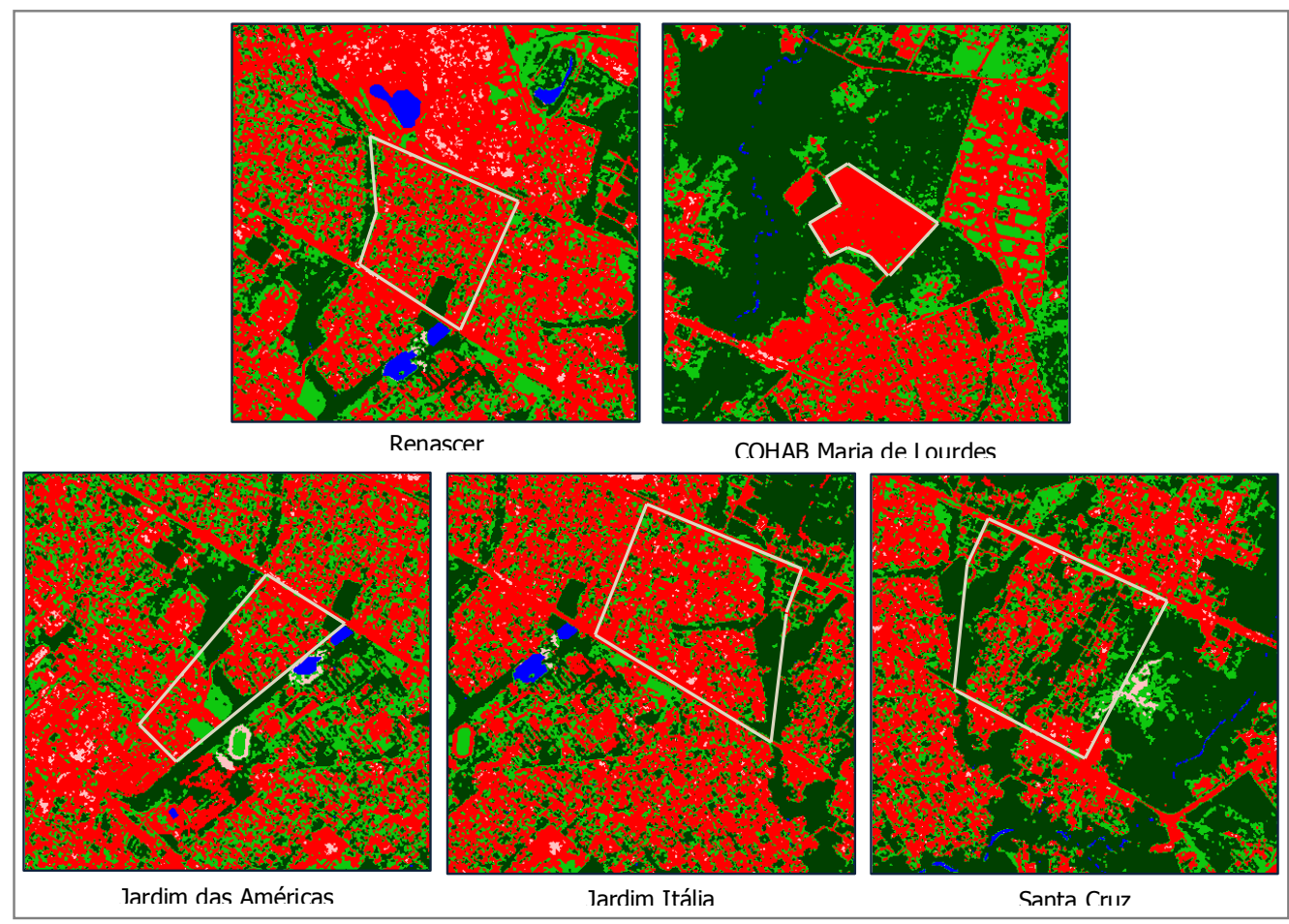

Figura 02 - Recortes das imagens classificadas $(2,5 \mathrm{~km}$ x 2,5 km).

\section{5 Área e Dimensão Fractal dos Fragmentos Arbóreos}

O estudo da relação entre o ambiente térmico de um lugar e o padrão espacial das áreas vegetadas do seu entorno próximo passa necessariamente pela definição da extensão dessa influência, afinal conforme a extensão do raio desses recortes do espaço urbano diferentes serão os percentuais de vegetação arbórea e os valores da dimensão fractal dessa classe.

Assim, para a determinação da extensão dessa influência, considerando a escala climática local para o delineamento experimental do estudo, optou-se por realizar nas imagens classificadas recortes internos sucessivos com aproximadamente metade do raio anterior, a partir de um recorte com um raio de influência de $1 \mathrm{~km}$, até o raio de influência de $10 \mathrm{~m}$ para cada um dos 250 pontos com registros de temperatura. Segundo Monteiro (2003) e Abreu e Labaki (2010), a partir de um raio de aproximadamente $1 \mathrm{~km}$ as árvores sofrem influência dos dados climáticos das escalas macroclimáticas e mesoclimáticas.

Assim, cada um dos 250 pontos selecionados foram delimitados por 7 quadrados concêntricos, as áreas de influência, que correspondem aos raios de 1000 m, 500 m, 200 m, 100 m, 50 m, 20 m e 10 m, conforme exemplificado na Figura 03. 

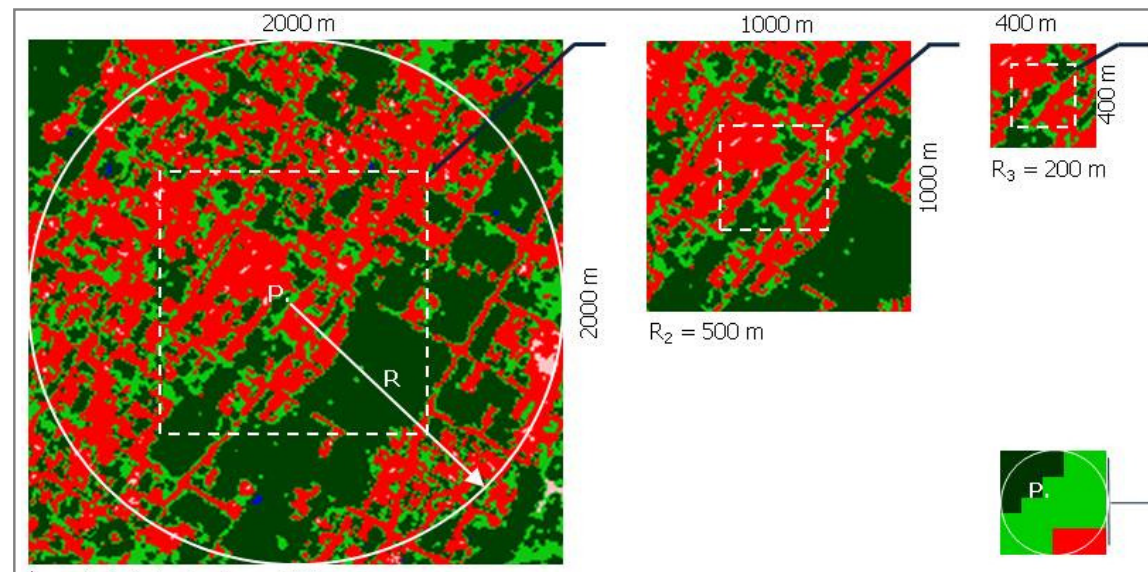

$200 \mathrm{~m} \times 200 \mathrm{~m}$

Área de Influência: $R_{1}=1000 \mathrm{~m}$

Figura 03 - Exemplo das áreas de influência de um ponto de medição.

Todos esses recortes foram submetidos ao software FRAGSTATS 3.3 (MCGARIGAL \& MARKS, 1995) para determinação das métricas da paisagem: área dos fragmentos e dimensão fractal. Este aplicativo foi utilizado com sucesso em alguns estudos urbanos recentes para quantificar a estrutura da paisagem e analisar as relações existentes entre seus elementos (DIBARI, 2007; STYERS et al., 2010). Neste trabalho, conforme a descrição de McGarigal e Marks (1995), foram utilizadas as métricas descritas a seguir.

\subsection{1 Área da Classe (Class Area - CA)}

A métrica, expressa em hectare, corresponde a área total de uma classe i dentro da paisagem, calculada pela soma das áreas, em $\mathrm{m}^{2}$, de todos os fragmentos $\mathrm{j}$ correspondentes a mesma classe.

$$
C A=\sum_{j=1}^{n} a_{i j}\left(\frac{1}{10000}\right)
$$

Onde $a_{i j}$ é a área do fragmento $\mathrm{j}$ da classe i em $\mathrm{m}^{2}$.

\subsubsection{Dimensão Fractal dos Fragmentos Ponderada pela Área (Area-Weighted Mean Patch Fractal Dimension - FRAC)}

A dimensão fractal varia entre 1 e 2, para um fragmento bi-dimensional. Valores próximos a 1 indicam formas com perímetros muito simples, como círculos ou quadrados. Polígonos mais complexos têm seus perímetros aumentados, também ocupando mais área, de forma que o valor do índice FRAC se aproxima de 2. O índice supera as limitações de outros índices que relacionam perímetro e área, interessantes por refletirem a complexidade da forma. 


$$
F R A C=\sum_{j=1}^{n}\left\{\left(\frac{2 \ln \left(0,25 p_{i j}\right)}{\ln a_{i j}}\right)\left(\frac{a_{i j}}{\sum_{j=1}^{n} a_{i j}}\right)\right\}
$$

Equação 02

Os termos $a_{i j}$ e $p_{i j}$ expressam, respectivamente, a área, em $\mathrm{m}^{2}$, e o perímetro, em $\mathrm{m}$, do fragmento $\mathrm{j}$ da classe $\mathrm{i}$, e $\mathrm{n}_{\mathrm{i}}$ é o número de fragmentos da classe $\mathrm{i}$.

A métrica FRAC foi ponderada pela área de cada fragmento, assim para a sua determinação os fragmentos maiores tiveram maior peso no cálculo que os fragmentos menores.

\subsection{Forma de análise dos resultados}

\subsubsection{Tratamento Geoestatístico das Medidas Móveis}

Apesar dos valores das temperaturas oscilarem em até $2,5{ }^{\circ} \mathrm{C}$ para um mesmo ponto de referência entre os dias de medições de uma mesma semana a análise dos resultados sugeriu uma tendência de comportamento ao longo dos transectos, onde, com poucas exceções, os pontos em que ocorreram os maiores e os menores registros de temperatura do ar não variaram conforme o dia em que foi realizado o transecto. Desta forma, ao invés de considerar bases de dados de temperaturas médias dos períodos de coletas, neste estudo para a escolha dos transectos utilizados como representativos dos horários padrões optou-se por um tratamento geoestatístico dos registros da temperatura do ar.

Realizada pelo software Gama Design v.5.0.3, a análise geoestatística definiu as escolhas dos transectos para expressarem o ambiente térmico de cada horário com base no critério do semivariograma cujo ajuste resultou em maior valor do coeficiente de determinação $\left(R^{2}\right)$. A condição sugere que nestas situações a variável temperatura do ar apresentou a maior dependência espacial.

\subsubsection{Ajuste de Curvas}

Contando com um banco de dados com 250 pontos, cada um associado a seis temperaturas do ar, para os três horários das duas estações, e 7 áreas de influência, cada uma associada a um valor de dimensão fractal e uma área dos fragmentos arbóreos, buscou-se, através de técnicas de regressão, por funções que explicassem da maneira mais simples as relações entre os grupos temperatura do ar e percentual de vegetação arbórea, e temperatura do ar e dimensão fractal dos fragmentos arbóreos.

Para tanto foi utilizado o aplicativo de regressão linear e não-linear TableCurve 2D v.5.1.1 para ajuste das funções de uma variável independente, que seriam os percentuais de área verde e a dimensão fractal das áreas verdes de um dado recorte, para uma variável a ser explicada, a temperatura do ar associada ao núcleo do sistema indicado em cada recorte.

\section{RESULTADOS}

\subsection{Temperatura do Ar x Percentual de Vegetação Arbórea}

Para avaliar a força da relação entre a temperatura do ar em um ponto e a área vegetada existente no entorno próximo deste, além de estimar a extensão da sua influência foram 
realizadas regressões simples assumindo uma possível relação linear entre as variáveis: o percentual de áreas verdes, a variável independente ou explicativa, e a temperatura do ar, a variável dependente ou variável a ser explicada.

As regressões testaram a força da relação entre as variáveis em cada uma das sete áreas de influência. Assim, foi assumido como a extensão da área de influência da vegetação arbórea sobre a temperatura do ar de um lugar aquele raio de influência cuja regressão resultou em um maior valor do coeficiente de determinação $R^{2}$. Esta estatística expressa a porcentagem da variável dependente que é explicada pela variável independente.

Os resultados foram apresentados em um gráfico de espalhamento, uma representação gráfica da relação entre as variáveis. Também foram apresentados os parâmetros da reta de regressão, a e b, o erro padrão (Std Error), o valor-t (t-value), o intervalo de confiança (95\% Confidence Limits), o teste da hipótese $(P>/ t /)$, além do valor do coeficiente de determinação.

\subsubsection{Raios de Influência para a Estação Seca}

A figura 04 apresenta os resultados da regressão linear realizada para o transecto do horário de $08 \mathrm{~h}$ da estação seca.

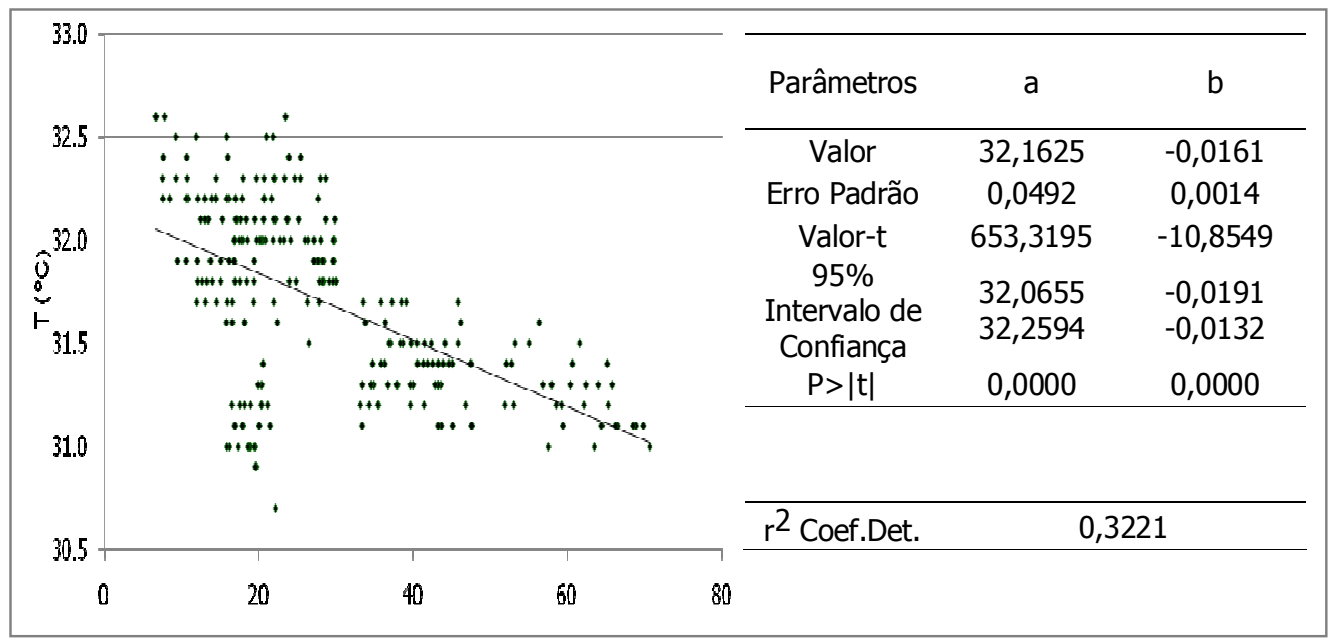

Figura 04 - Distribuição da temperatura do ar às $08 \mathrm{~h}$ da estação seca em função do percentual de área verde para um raio de influência de $500 \mathrm{~m}$.

Nestas condições os percentuais dos fragmentos arbóreos apresentaram uma maior relação com a temperatura do ar para um raio de influência de $500 \mathrm{~m}$. Para este raio de influência a estatística $R^{2}$ permitiu inferir que a vegetação arbórea pode explicar $32,21 \%$ da variação da temperatura do ar para este horário nesta estação.

Para o horário de $14 \mathrm{~h}$ da estação seca as áreas dos fragmentos de vegetação arbórea também apresentaram uma relação mais forte com a temperatura do ar para um raio de influência de $500 \mathrm{~m}$ (Figura 05). 


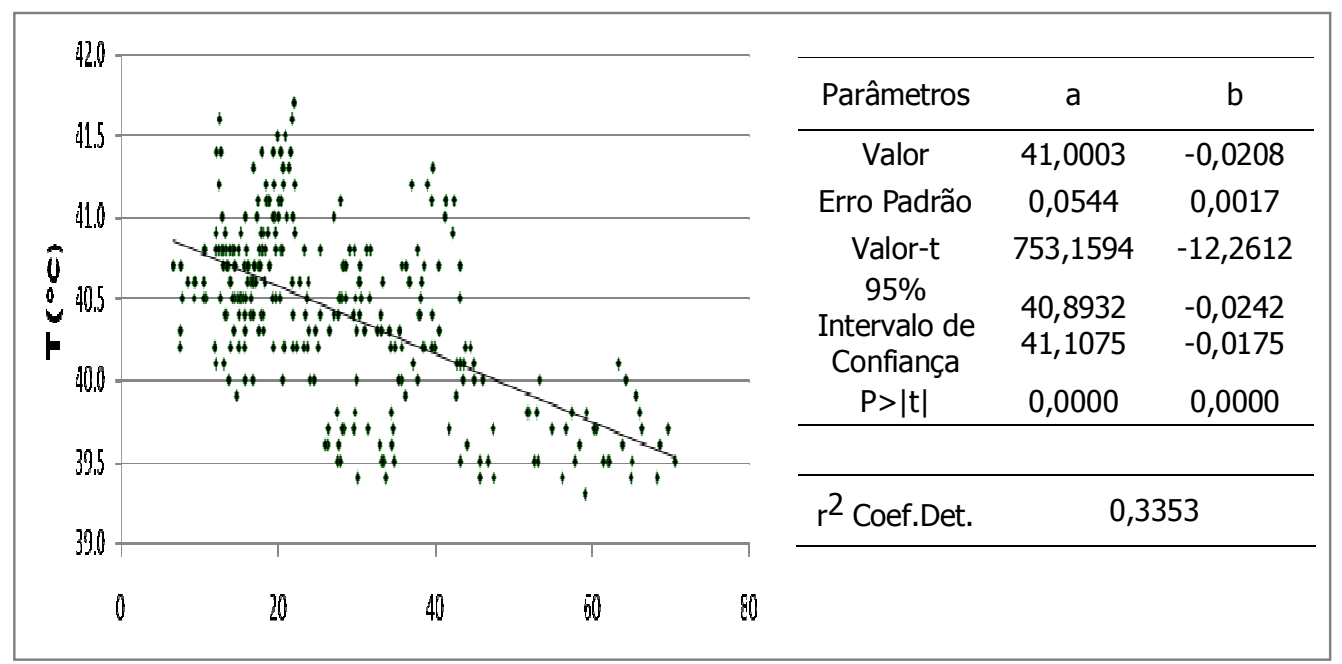

Figura 05 - Distribuição da temperatura do ar às $14 \mathrm{~h}$ da estação seca em função do percentual de área verde para um raio de influência de $500 \mathrm{~m}$.

Para este raio de influência, segundo o resultado da estatística $R^{2}$, a área vegetada pode explicar 33,53\% da variação da temperatura do ar para este horário nesta estação.

No horário noturno da estação seca a relação entre as variáveis apresentou maior força que nos outros horários, de forma que os fragmentos de vegetação arbórea do ambiente urbano explicaram $61,16 \%$ da variação da temperatura do ar para o horário nesta estação (Figura 06).

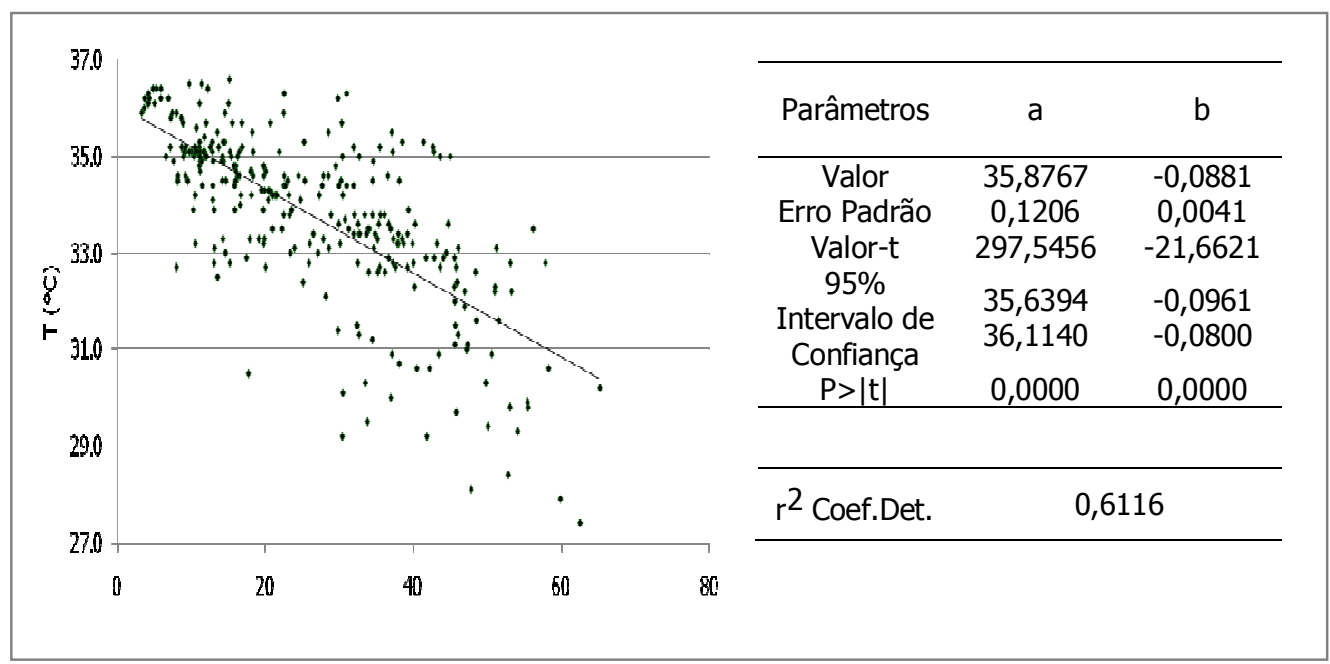

Figura 06 - Distribuição da temperatura do ar às $20 \mathrm{~h}$ da estação seca em função do percentual de área verde para um raio de influência de $200 \mathrm{~m}$. 
Na medição noturna da estação seca, as áreas dos fragmentos arbóreos apresentaram maior relação com a temperatura do ar para um raio de influência de $200 \mathrm{~m}$.

\subsubsection{Raios de Influência para a Estação Chuvosa}

A figura 07 apresenta os resultados da regressão linear realizada para o transecto do horário de $08 \mathrm{~h}$ da estação chuvosa.

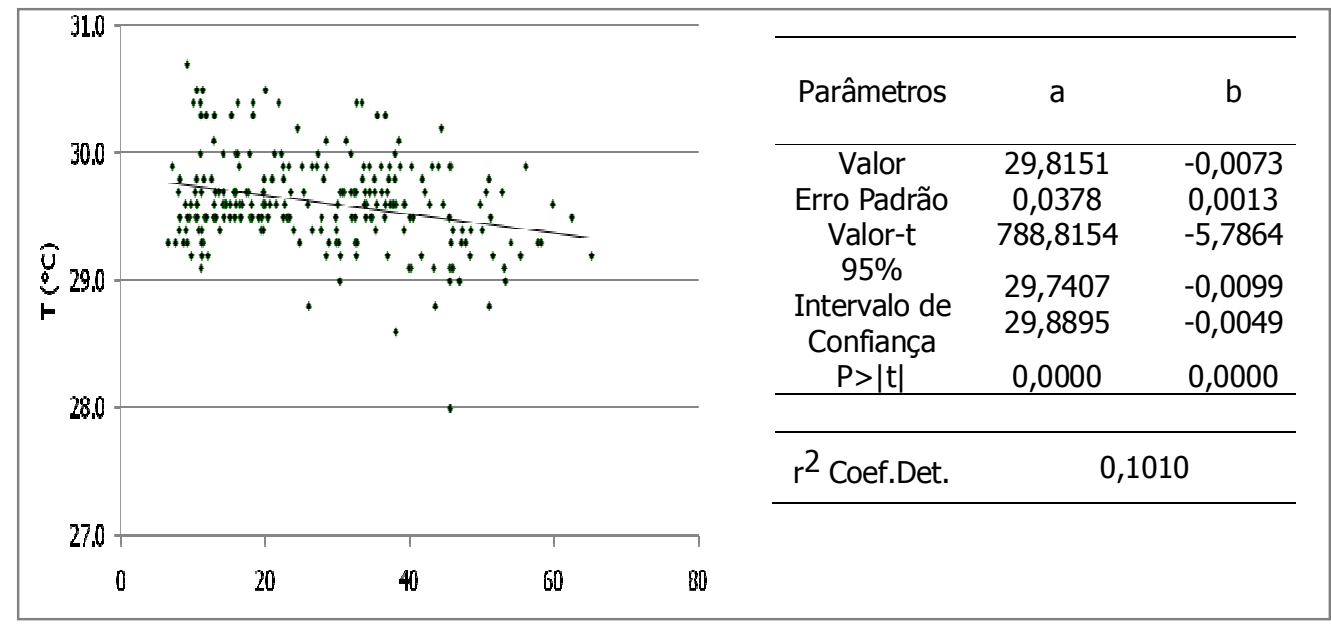

Figura 07 - Distribuição da temperatura do ar às 08 h da estação chuvosa em função do percentual de área verde para um raio de influência de $200 \mathrm{~m}$.

Nestas condições os percentuais dos fragmentos arbóreos apresentaram uma maior relação com a temperatura do ar para um raio de influência de $200 \mathrm{~m}$. Para este raio de influência a estatística $R^{2}$ permitiu inferir que a vegetação arbórea pode explicar $10,10 \%$ da variação da temperatura do ar para este horário nesta estação, a relação mais fraca entre todos os transectos.

Para o horário de $14 \mathrm{~h}$ da estação chuvosa, as áreas dos fragmentos de vegetação dos ambientes apresentaram uma relação mais forte com a temperatura do ar para um raio de influência de 500 m (Figura 08).

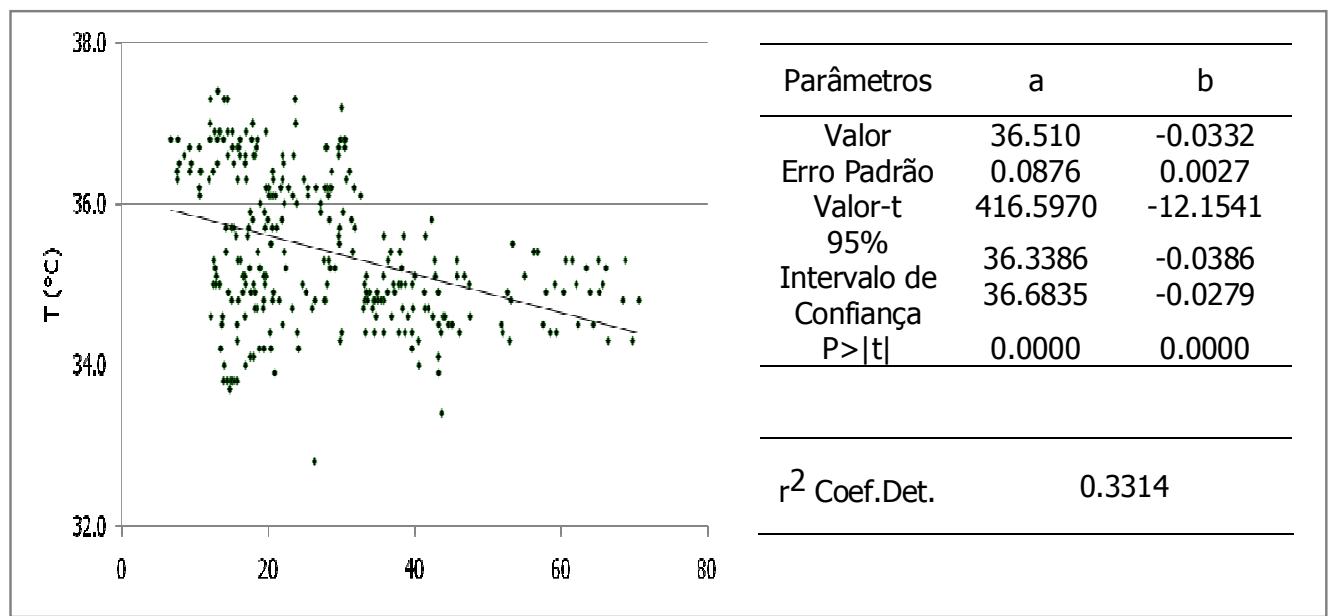

Figura 08 - Distribuição da temperatura do ar às 14 h da estação chuvosa em

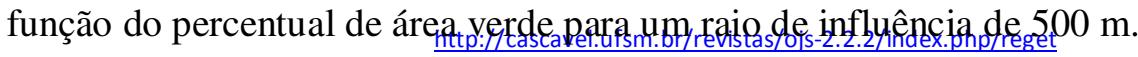


Para este raio de influência, segundo o resultado da estatística $R^{2}$, a área vegetada pode explicar 33,14\% da variação da temperatura do ar para o horário nesta estação.

Na medição noturna da estação chuvosa, as áreas dos fragmentos arbóreos apresentaram maior relação com a temperatura do ar para um raio de influência de 200 m (Figura 09).

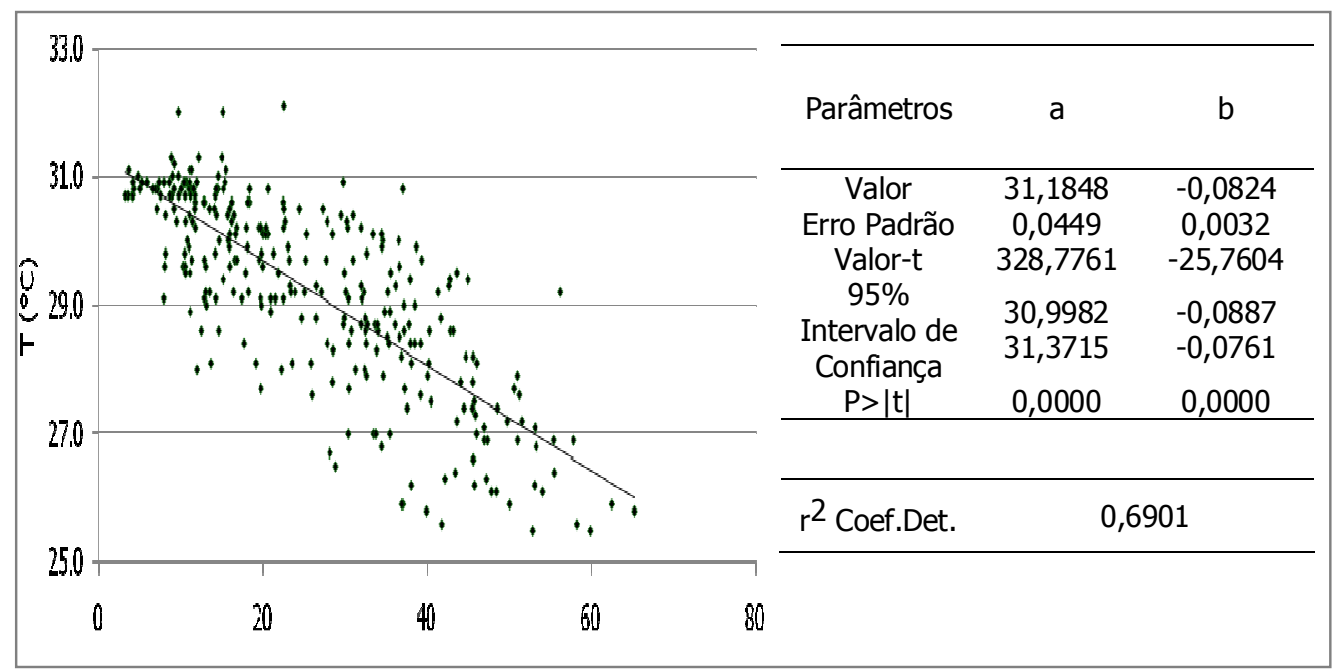

Figura 09 - Distribuição da temperatura do ar às 20 h da estação chuvosa em função do percentual de área verde para um raio de influência de $200 \mathrm{~m}$.

No horário de 20 h da estação chuvosa, como ocorreu na estação seca, a relação entre as variáveis apresentou maior força que nos outros horários, de forma que os fragmentos de vegetação arbórea do ambiente urbano explicaram $69,01 \%$ da variação da temperatura do ar para o horário nesta estação.

Estes resultados confirmaram a existência da relação entre a temperatura do ar de um lugar com a presença de fragmentos arbóreos em seu entorno próximo. A força da relação avaliada pelo ajuste linear serviu apenas para indicar a tendência observada, de que recortes com menores percentuais de área verde geralmente implicam em maiores temperaturas do ar, uma vez que não se pretendia neste trabalho tomar a equação da regressão como preditiva dos valores da temperatura do ar. Ainda assim, a análise de variância mostrou que a regressão foi adequada, pelo seu nível de significância, $p$-valor $=0,000$, onde rejeita-se a hipótese nula, de não haver relação entre as variáveis a um nível de significância de $5 \%$.

A relação mais fraca foi encontrada na estação chuvosa para o horário de $08 \mathrm{~h}$. A elevada umidade do ar e dos solos nesta época e horário faz com que a razão de Bowen seja bastante reduzida, de forma que a radiação, ainda pouco intensa, atua de forma discreta sobre os ambientes térmicos produzindo microclimas muito semelhantes. 
As diferenças na razão de Bowen e no índice de área foliar ${ }^{2}$ (IAF) das vegetações nas duas estações do ano também podem explicar as variações nos raios de influência das áreas vegetadas para os mesmos horários entre os períodos seco e a chuvoso. A ausência de precipitações associada às características da vegetação predominante nos terrenos mais elevados da área, o cerrado stricto sensu, com árvores decíduas que apresentam perda parcial de folhas justificam a redução do IAF para a estação seca.

Aparentemente, os resultados indicaram que o raio de influência de um fragmento arbóreo sobre o ambiente térmico de um lugar varia entre 200 m e 500 m dependendo da época do ano e do horário, alcançando valores maiores no período diurno e reduzindo sua extensão no período noturno. Estes resultados também sugerem que o percentual de vegetação arbórea de uma região delimitada não tem peso sobre a extensão da influência, mas afeta fortemente a intensidade desta.

No período noturno a inexistência da radiação solar, faz com que cada espaço urbano atue como operador da dinâmica temporal, um núcleo de um sistema que irradiando a energia incorporada ao longo dia mantém o ar a sua volta aquecido por mais tempo. Com menor quantidade de energia incorporada, os microclimas das regiões de áreas vegetadas, como que pressionados, sofrem a atuação das adjacências de forma que seu raio de influência é reduzido neste período. Confirmando as suspeitas, apesar do menor raio de influência, no período noturno ficou mais evidente a força da influência da vegetação sobre a temperatura do ar nos ambientes urbanos.

Uma observação mais apurada dos gráficos de espalhamento mostrou que em algumas situações pontos com percentuais iguais de áreas verdes apresentaram variações de temperatura de até $4{ }^{\circ} \mathrm{C}$, sugerindo que esta variável pode não atuar sozinha sobre o microclima de um lugar. $\mathrm{O}$ conjunto de outras variáveis como presença de corpos de água, altitude, propriedades térmicas dos revestimentos são também explicativas para o ambiente térmico de um lugar. Características fisiológicas da vegetação, como IAF e altura do dossel, e a estrutura, o padrão, da distribuição destas áreas verdes também podem explicar em parte essas variações de temperatura encontradas.

\subsection{Temperatura do Ar x Fragmentação das Áreas Verdes}

A dimensão fractal, como medida da fragmentação de uma área ou ainda como o nível de ocupação do espaço pela forma, foi utilizada nesta análise para tentar avaliar que padrão espacial, mais ou menos fragmentado, devem apresentar as áreas vegetadas dos ambientes urbanos para que sua função de amenização climática seja melhor aproveitada.

Para esta avaliação os 250 pontos da base de dados, com as respectivas temperaturas para cada transecto e valores da dimensão fractal das áreas vegetadas para todos os raios de influência propostos neste trabalho, foram submetidos ao aplicativo TableCurve 2D v.5.1.1 com a intenção de encontrar uma função que melhor explicasse a possível relação entre essas variáveis.

As curvas que melhor se ajustaram aos pontos de cada transecto e os respectivos raios de influência em função dos maiores coeficientes de determinação $\left(R^{2}\right)$ são apresentados na Figura 10. Sobre os diagramas, para auxiliar na explicação do comportamento das variáveis, foram plotados os pontos, classificados pelos percentuais de áreas verdes dos recortes, que apresentaram as maiores e as menores temperaturas do transecto e os maiores e os menores valores da dimensão fractal dessas áreas verdes.

\footnotetext{
${ }^{2}$ Variável biofísica, diretamente relacionada com a evapotranspiração, é definida como sendo a razão entre o total de área foliar do dossel da vegetação pela área da superfície projetada no solo.
} 
A função de resposta Weibull foi o melhor modelo paramétrico para ajustar as curvas. Outras funções, aplicadas a estes mesmos dados, produziram valores mais interessantes para a estatística $R^{2}$, sem, no entanto, trazer luz a dúvida levantada. Proposta pelo engenheiro e matemático sueco Ernst Weibull, a distribuição Weibull tem origem a partir do estudo das distribuições das dimensões de partículas após uma fragmentação, assumindo que partículas pequenas são mais prováveis do que as partículas maiores ao final do processo, de forma que a fragmentação é um processo regido por uma função de potência (BROWN \& WOHLETZ, 1995).

As curvas, em todos os horários e estações, apresentaram uma mesma tendência, sugerindo a existência da relação entre a temperatura do ar de um lugar, não apenas com a extensão dos fragmentos arbóreos de seu entorno próximo, bem como com o padrão como estes estão dispostos neste ambiente. A força da relação, avaliada no ajuste da curva pelo coeficiente de determinação $R^{2}$, foi muito pequena em todas as curvas, porém, como na situação anterior, o traçado da curva teve a finalidade de indicar uma tendência, difícil de ser observada sem tal artifício. 
Rev. Elet. em Gestão, Educação e Tecnologia Ambiental (e-ISSN: 2236-1170)

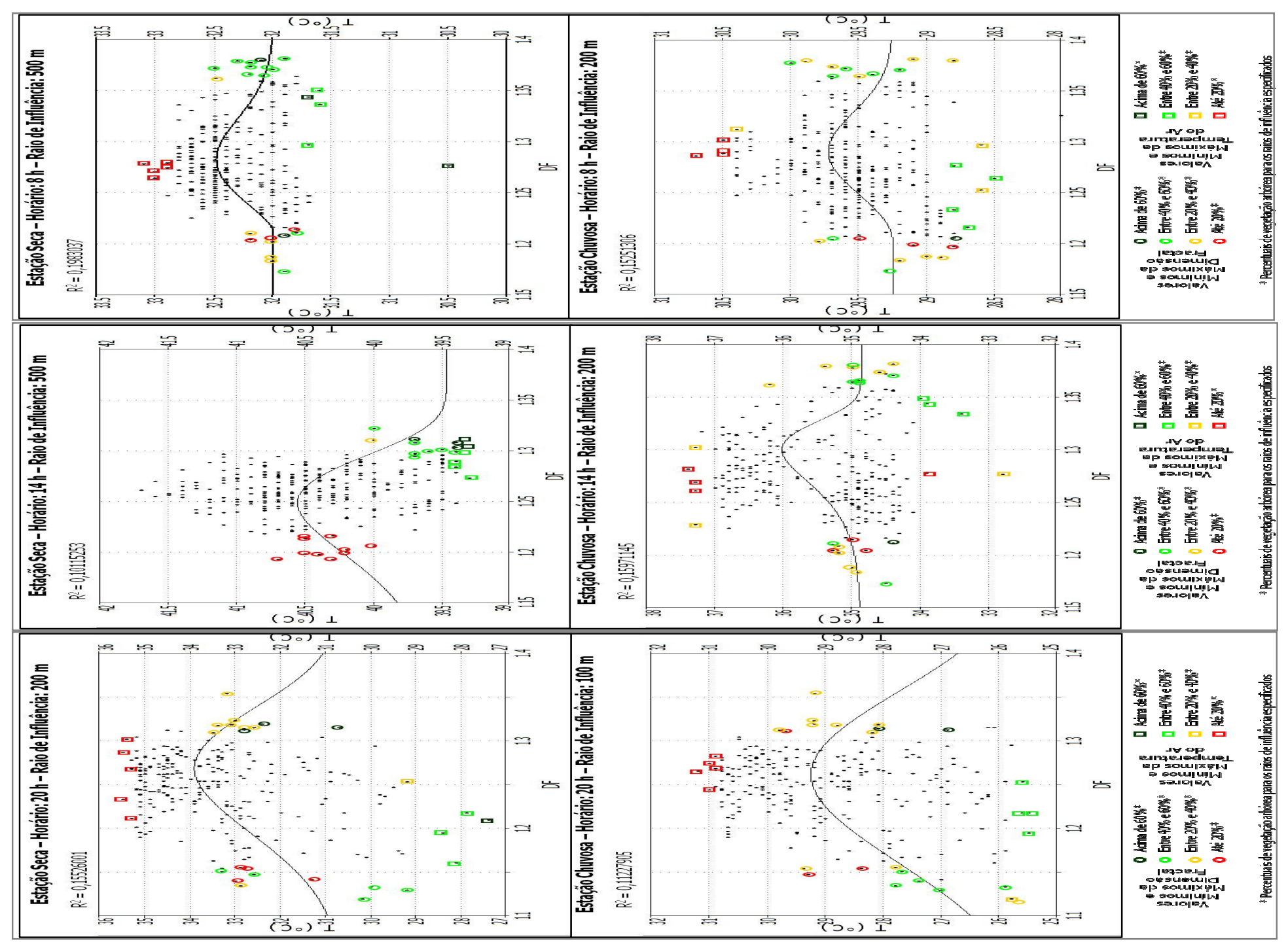

Figura 10 - Ajuste da curva dimensão fractal das áreas verdes em função da temperatura do ar. 
As assíntotas destas curvas nesta aplicação apontaram para as menores temperaturas do ambiente nos limites extremos da dimensão fractal: menor dimensão fractal correspondendo a fragmentos arbóreos de formatos regulares e maior dimensão fractal correspondendo a fragmentos arbóreos com formatos bastante complexos, porém definindo em ambos os casos áreas completamente vegetadas.

Ligeiramente diferente entre os horários dos transectos, as curvas se assemelharam para os mesmos horários nas duas estações. Como no processo geoestatístico, a dimensão fractal das áreas verdes também melhor se ajustou aos raios de influência na faixa de $200 \mathrm{~m}$ a $500 \mathrm{~m}$, com extensão de influência também reduzida na estação chuvosa em comparação com a seca.

$\mathrm{Na}$ estação seca os pontos pareceram mais concentrados na região da curvatura da função, em uma faixa restrita de valores da dimensão fractal. A observação sugere que nesta estação do ano a fragmentação das áreas verdes teve menor influência sobre os ambientes térmicos destes espaços, que foram melhor explicados pelo percentual de áreas verdes existentes em cada recorte de influência. Na estação seca, a maior interação entre atmosfera e superfície proporcionada pela baixa umidade resultou em grandes amplitudes térmicas, de forma que a influência das áreas vegetadas pôde ser verificada a uma distância maior que aquela verificada na estação úmida.

Os pontos plotados sobre as curvas permitiram perceber que a fragmentação atua com maior força sobre as áreas com percentuais menores de área vegetada, de até $20 \%$ da área total. Nestes recortes uma maior fragmentação das áreas verdes, ou seja valores mais elevados da dimensão fractal, implicaram em lugares com temperaturas mais elevadas. A análise dos dados também mostrou que mais da metade dos pontos amostrados para este trabalho apresentaram áreas verdes com extensões inferiores a $20 \%$ dos recortes que ocupam.

Recortes com percentuais maiores de áreas vegetadas apresentaram temperaturas reduzidas, com redução proporcional a extensão destes, sob quaisquer valores do índice de fragmentação, de forma que as implicações da fragmentação são reduzidas sobre esses recortes. Todavia, os recortes com percentuais elevados de áreas verdes com maiores valores de dimensão fractal, fragmentados mas conectados, formando contínuos, podem atuar no sistema clima urbano fragmentando as grandes manchas urbanizadas, reduzindo a intensidade da influência destas.

\section{CONCLUSÃO}

As análises estatísticas dos dados provenientes do monitoramento do ambiente térmico desta região da cidade de Cuiabá, $\mathrm{MT}$, conduziram a resultados que, além de confirmarem a hipótese de que as áreas vegetadas influenciam a temperatura do ar do entorno próximo, demonstraram a extensão desta influência, que variou conforme o período do dia e a estação do ano, maior na seca, reduzida na úmida. Segundo a distribuição Weibull aplicada aos dados, a temperatura do ar seria a menor possível em um dado lugar e horário se a área de influência do seu ambiente térmico fosse completamente vegetada.

A definição dos pontos de transição de um ambiente climático para outro permitiu concluir que o padrão de distribuição das áreas de vegetação arbórea também contribuiu para a formação dos ambientes térmicos urbanos. Em recortes do espaço urbano com baixos percentuais de área vegetada, inferiores a $20 \%$ da área de influência, a fragmentação dessa vegetação, medida de difícil quantificação, neste estudo descrita com muita propriedade pela dimensão fractal, atuou de forma mais decisiva nos ambientes térmicos, sendo que nesses casos uma vegetação mais fragmentada resultou, mesmo que discretamente, em redução de temperatura do ar. 
As melhores condições de amenização climática ocorreram em recortes com percentuais elevados de áreas verdes e com maiores valores de dimensão fractal, de forma a se apresentarem fragmentados e conectados. Neste sentido, balizando o planejamento do crescimento urbano em função da melhor ambiência destes espaços, a recuperação dos inúmeros córregos que cortam a cidade e a reconstituição da vegetação que os acompanha, constituída em parques urbanos, associadas a conservação das pequenas áreas verdes e a um programa efetivo de arborização de praças e vias públicas são políticas públicas que podem fornecer para cada bairro da cidade o percentual e a distribuição das áreas verdes suficientes para uma melhor ambiência nestes espaços urbanos.

\section{AGRADECIMENTO}

Agradecemos a Universidade Federal de Mato Grosso, na pessoa do Prof. Dr. José de Souza Nogueira, Coordenador do Programa de Pós-Graduação em Física Ambiental, por tornar possível a realização deste trabalho.

\section{REFERÊNCIAS BIBLIOGRÁFICAS}

ABREU, L. V.; LABAKI, C. L. Conforto Térmico Propiciado por Algumas Espécies Arbóreas: avaliação do raio de influência através de diferentes índices de conforto. Ambiente Construído, v.10, n.4, p.103-117. Out. 2010.

BARROS, M. P.; NOGUEIRA, M. C. J. A.; MUSIS, C. R. O Projeto de Parque Urbano e os Riscos da Exposição ao Calor. Ambiente Construído, v.10, n.2, p.147-156. Abr. 2010.

BROWN, W. K.; WOHLETZ, K. H. Derivation of the Weibull Distribution Based on Physical Principles and its Connection to the Rosin-rammler and Lognormal Distributions, J. Appl. Phys., v.78, n.4, p.2758-2763, Ago. 1995.

CAMPELO JÚNIOR, J. H.; CASEIRO, F. T.; PRIANTE FILHO, N.; BELLO, G. C. C.; MAITELLI, G. T.; ZAMPARONI, C. A. G. P. Caracterização Macroclimática de Cuiabá. In: ENCONTRO NACIONAL DE ESTUDOS SOBRE O MEIO AMBIENTE, 3, 1991. Londrina. Anais. Londrina, PR: FUEL, 1991. p.545552.

DIBARI, J. N. Evaluation of Five Landscape-level Metrics for Measuring the Effects of Urbanization on Landscape Structure: the case of Tucson, Arizona, USA. Landscape and Urban Planning, v.79, n.3-4, p.308-313. Mar. 2007.

DIMOUDI, A.; NIKOLOPOULOU, M. Vegetation in the Urban Environment: microclimatic analysis and benefits. Energy and Buildings, v.35, n.1, p. 69-76. Jan. 2003.

FUKUI, Y. A Study on Surface Temperature Patterns in the Tokyo Metropolitan Area Using ASTER Data. Geosciences Journal, v.7, n.4, p.343-346. Dez. 2003.

GONÇALVES, C. D. A. B.; PEREIRA, M. N.; SOUZA, I. M. Uso de Imagens CBERS Para Mapeamento de Uso do Solo Urbano como Subsídio ao Planejamento. In: SIMPÓSIO BRASILEIRO DE SENSORIAMENTO REMOTO, 12, 2005, Goiânia. Anais. Goiânia, GO: INPE, 2005. p.969-977. 
INSTITUTO NACIONAL DE PESQUISAS ESPACIAIS - INPE. SPRING: Sistema de Processamento de Informações Georreferenciadas, 2009. Disponível em: <http://www.dgi.inpe.br/spring>. Acesso em 12 jul. 2009.

JUSUF, S. K.; WONG, N. H.; HAGEN, E.; ANGGORO, R.; HONG, Y.; CHEN, Y. Study of Green Areas and Urban Heat Island in a Tropical City. Habitat International, v.31, n.2, p.232-242. Jun. 2007.

KAISER, I. M.; FARIA, J. R. G. Validation of Transects For Air Temperature and Moisture Profiles Measurements in Urban Areas Under High Diurnal Air Temperatures Variation. In: INTERNATIONAL CONFERENCE ON PASSIVE AND LOW ENERGY ARCHITECTURE, 18, 2001, Florianópolis. Anais. Florianópolis, SC: PLEA/ANTAC/UFSC, 2001, p.571-575.

MAITELLI, G. T. Interações Atmosfera-Superfície. In: Morene G.; Higa T. C. S. organizadores. Geografia de Mato Grosso: território, sociedade e ambiente. Entrelinhas: Cuiabá, 2005. 296p.

MCGARIGAL, K.; MARKS, B. J. FRAGSTATS: Spatial pattern analysis program for quantifying landscape structure. Gen. Tech. Rep. PNW-GTR-351. Department of Agriculture, Forest Service, Pacific Northwest Research Station: Portland, USA, 1995. 132p.

MONTEIRO, C. A. F. Teoria e Clima Urbano. In: Monteiro C. A. F.; Mendonça F. organizadores. Clima Urbano. Contexto: São Paulo, 2003. 192p.

NOVACK, T.; KARAM, H. A.; LUCHIARI, A.; CLARO, M. S.; PEREIRRA FILHO, A. J. Mapeamento Automático de Padrões de Urbanização e Cobertura da Terra na Região Metropolitana de São Paulo Utilizando Imagens CCD-CBERS-2. In: SIMPÓSIO BRASILEIRO DE SENSORIAMENTO REMOTO, 13, 2007, Florianópolis. Anais. Florianópolis, SC: INPE, 2007. p.1001-1008.

OKE, T. R. The Energetic Basis of the Urban Heat Island. Quarterly Journal of the Royal Meteorological Society, v.108, n.455, p.1-24. Jan. 1982.

PEZZUTO, C. C. Avaliação do Ambiente Térmico nos Espaços Urbanos Abertos. Estudo de caso em Campinas, SP. 2007. Tese (Doutorado em Engenharia Civil) Faculdade de Engenharia Civil, Arquitetura e Urbanismo, Universidade Estadual de Campinas. 197f. Campinas, SP.

SAARONI, H.; BEN-DOR, E.; BITAN, A.; POTCHTER, O. Spatial Distribution and Microscale Characteristics of the Urban Heat Island in Tel-Aviv, Israel. Landscape and Urban Planning, v.48, n.1-2, p.1-18. Abr. 2000.

STYERS, D. M.; CHAPPELKA, A. H.; MARZEN, L. J.; SOMERS, G. L. Developing A Land-cover Classification To Select Indicators Of Forest Ecosystem Health In A Rapidly Urbanizing Landscape. Landscape and Urban Planning, v. 94, n.3, p.158-165. Mar. 2010.

YU, C.; WONG, N. H. Thermal Benefits of City Parks. Energy and Buildings, v.38, n.2, p.105-120. Fev. 2006. 


\section{Identificação dos Autores:}

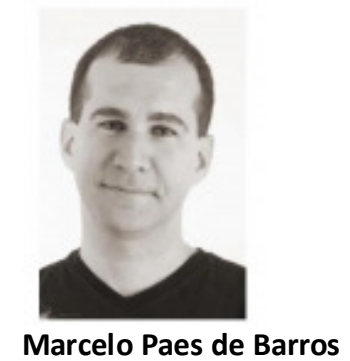

Graduação em Engenharia Civil pela Universidade Federal de Mato Grosso/ UFMT; Professor Efetivo do Instituto de Física/ UFMT;

Doutor pelo Programa de Pós Graduação em Física Ambiental/ PPGFA/ UFMT, Linha de Pesquisa: Análise Microclimática em Sistemas Urbanos, E-mail: mpb9@terra.com.br

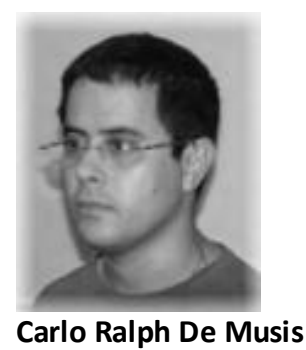

Graduação em Engenharia Civil pela Universidade Federal de Mato Grosso/ UFMT;

Professor Efetivo da Universidade de Cuiabá/ UNIC;

Professor do Programa de Pós-Graduação em Física Ambiental, Linha de Pesquisa: Análise Microclimáticas em Sistemas Urbanos, E-mail: carlo.demusis@gmail.com 